\title{
Late Occurrence of Traumatic Chylothorax in a Multi-Trauma Patient With a Thoracic Spine Fracture-Dislocation
}

\author{
Ioannis Siasios ${ }^{\mathrm{a}, \mathrm{b}}$, Charalambos Gatos ${ }^{\mathrm{a}}$, Anastasia Tasiou ${ }^{\mathrm{a}}$, Aggeliki Fotiadou, \\ Kostantinos Fountas ${ }^{\mathrm{a}}$
}

\begin{abstract}
Chylothorax is a rare form of chyle accumulation that can be associated with both traumatic and non-traumatic causes. We described a case of a patient who sustained a thoracic spine fracture-dislocation and presented with a left-sided chylothorax as a late complication to his thoracic spine trauma. A 19-year-old multi-trauma patient with bilateral pneumothorax, bilateral lung contusions and a severe thoracic spine fracture-dislocation was admitted to the intensive care unit (ICU) of our hospital intubated due to his unstable respiratory function. Bilateral thoracostomies were placed to his thoracic cavity prior to his admission to the ICU. The thoracic fracture-dislocation was stabilized with posterior fixation of his thoracic spine during his stay at the ICU. He was transferred to the neurosurgery department where at the 50th day of his hospitalization, a left-sided chylothorax was identified. Conservative management was decided and the chyle leak ceased over a period of 2 weeks. The patient was discharged from the clinic after a 3-month period of hospitalization. Traumatic chylothorax is a rare complication directly linked to thoracic spine fractures. It can occur immediately after trauma or several weeks after as in our case. Early diagnosis and treatment are essential for the avoidance of severe complications linked to the chyle loss.
\end{abstract}

Keywords: Thoracic fracture; Trauma; Chylothorax; Parenteral nutrition

\section{Introduction}

Chylothorax is defined as the accumulation of chyle into the chest cavity as a result of leakage from the thoracic duct. It may be located on the right or left or both sides, depending on the level of the ductal damage. Various malignancies including non-Hodgkin's lymphoma are associated with the occurrence

Manuscript accepted for publication November 04, 2015

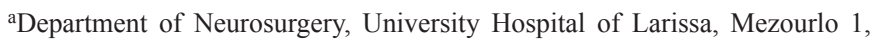
Larissa 41110, Greece

${ }^{b}$ Corresponding Author: Ioannis Siasios, Mezourlo 1, University Hospital of Larissa, Larissa 41110, Greece. Email: siasiosj@med.uth.gr

doi: http://dx.doi.org/10.14740/jmc2364w of chylothorax [1]. Thoracic spine fractures, anterior cervical spine surgery, neck surgery, cardiovascular surgery, thoracic tumor surgery and thoracic spine surgery as well as central venous line insertion are the more common causes for a thoracic duct injury [2-11]. Nutritional deficiencies, respiratory dysfunction, dehydration and immunological dysfunction can be caused by large chyle leaks [12]. Early diagnosis and treatment of traumatic chylothorax are crucial in avoiding these associated morbidities. We are reporting a rare case of a multi-trauma patient with a surgically treated thoracic spine fracture who developed chylothorax several days after his initial admission complicating his post-operative course.

\section{Case Report}

A 19-year-old man was referred to our neurosurgery department after a reported motor vehicle accident which resulted in a three column thoracic spine fracture and subsequent paraplegia. His initial clinical examination revealed bilateral chest wall tenderness to palpation, decreased breath sounds bilaterally, lower thoracic spine tenderness to palpation, a complete loss of motor function in his lower extremities and loss of sensory function below the level of T7. Patient also had a loss of his cremasteric and bulbar cavernous reflex, and he did not have rectal tone (ASIA A). The patient was intubated due to unstable breathing and low saturation. Reconstructed 3D computer tomography of his thoracic spine showed a fracture of $\mathrm{T} 7$ thoracic vertebrae and dislocation of T7 vertebra on T8 vertebra (Fig. 1). Rib fractures, bilateral pneumothorax, and lung contusions bilaterally were also found. After the placement of chest tube thoracostomies, patient was transferred to the intensive care unit (ICU) of our hospital where he stayed for 45 days (Fig. 2). During that period of time, he underwent posterior stabilization of his unstable thoracic spine fracture. Patient was transferred to the neurosurgery clinic after his discharge from the ICU where his left chest tube had a daily bloody drainage of $100 \mathrm{~mL}$. The right chest tube had been removed in the ICU. On the 50th day of his hospitalization and after the initiation of food uptake, the patient presented with milky white fluid excretion from his left-sided chest tube. Chest Xray and thoracic $\mathrm{CT}$ revealed an enlarged fluid pleural effusion at the base of his left lung (Fig. 3, 4). Biochemical analysis of the pleural fluid revealed triglycerides of $276 \mathrm{mg} / \mathrm{dL}$, total pro- 


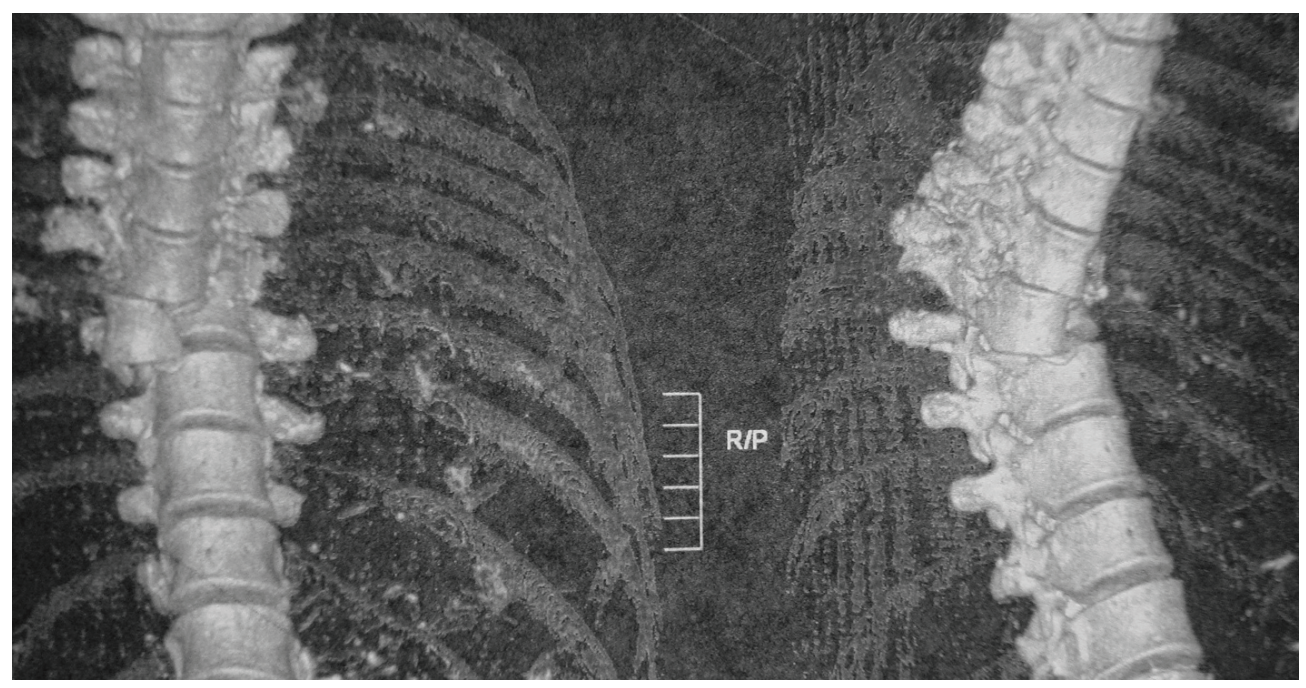

Figure 1. 3D reconstruction computer tomography of patient's thoracic spine demonstrating the T7 vertebra fracture-dislocation upon T8 vertebra.

tein of 2,200 mg/ dL, and LDH of 2,555 units/L. These results confirmed the presence of chylothorax. Conservative management was decided with total parenteral nutrition, a low-fat and medium-chain triglycerides diet and maintenance of the left drainage. The closure of the major thoracic duct was achieved over a period of 2 weeks. The chest tube was then removed and patient was started on a regular diet. Follow-up chest X-rays did not reveal any recurrent pleural effusions. His pulmonary status remained stable and the patient was discharged in order to participate in a rehabilitation program after a 3-month period of hospitalization.

\section{Discussion}

Chylothorax is a pathological condition with high mortality and morbidity rate $[13,14]$. Chylothorax associated with thoracic vertebral injury was noted first by Krabbell in 1885

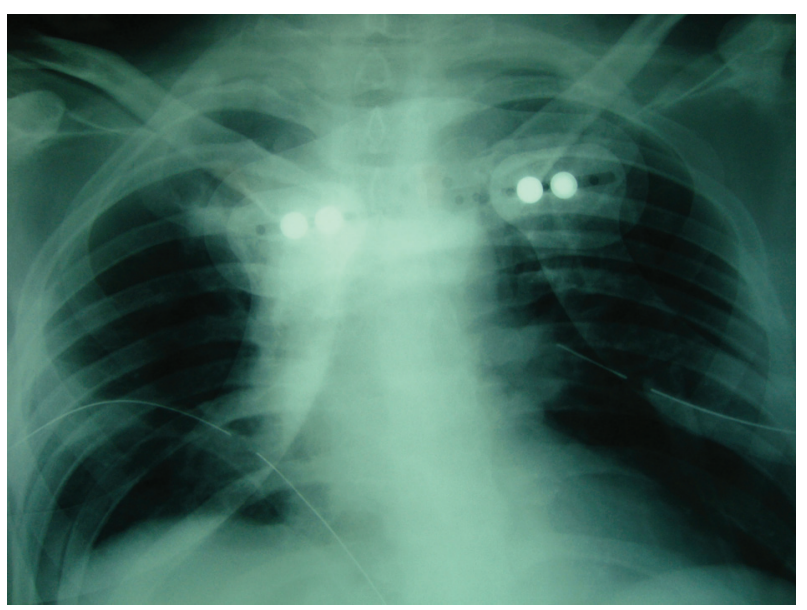

Figure 2. Chest X-ray demonstrating the bilateral thoracostomies that patient had during his initial presentation in the ICU.
$[15,16]$. Until today there have been described several cases in bibliography [11, 17-31]. Leturgie et al reported in 1979 a case of a patient with traumatic chylothorax in combination with a dorsal spine fracture [18]. Chylothorax was recognized at the 13th day of patient's hospitalization. Similarly, in all the other reported cases, chylothorax was noted immediately to several days after injury occurrence. In our case, chylothorax was noted 50 days after injury took place which is rarely documented in the literature. There is only one other case report in the literature in which chylothorax was described 20 years after a blunt thoracic trauma [31].

Generally, chyle extravasation could be caused by two major mechanisms. Chylothorax could be either a result of direct trauma to the lymphatic vessels in the chyle pathway or either the result of thoracic chyle duct occlusion. Clinical manifestations of chylothorax are: 1) hypovolemia due to large amount of chyle loss, 2) dyspnea, 3) malnutrition due to the loss of protein, fats and vitamins, 4) hyponatremia, 5) hypocal-

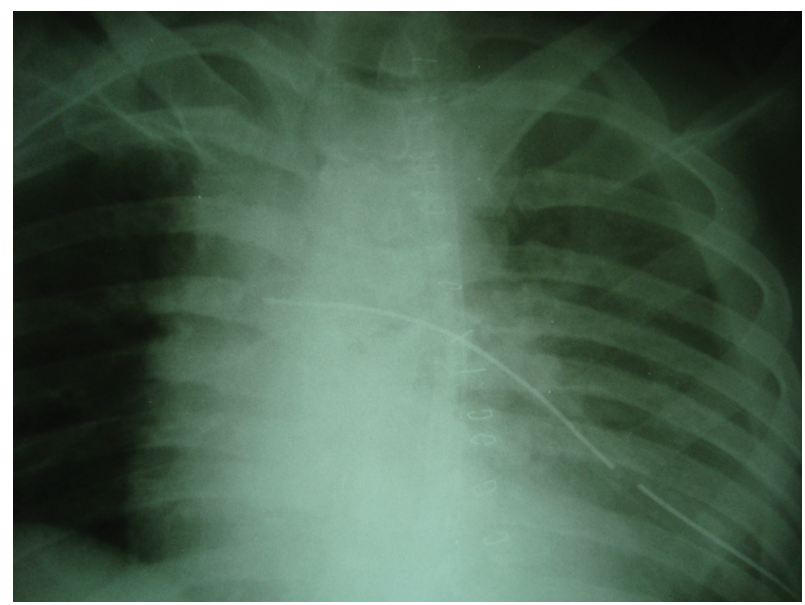

Figure 3. Chest X-ray demonstrating the chyle concentration in the base of patient's left lung. 


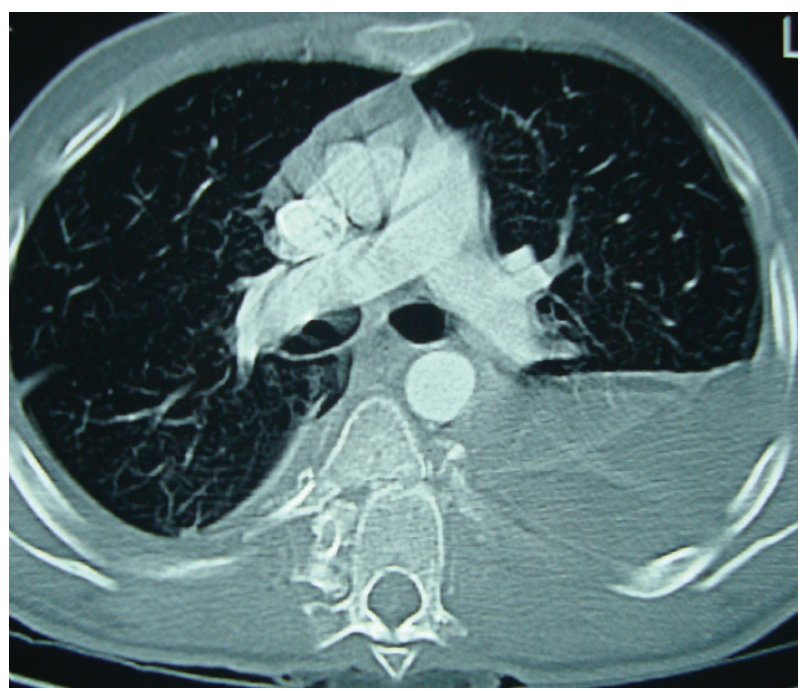

Figure 4. Axial contrast computer tomography of patient's thoracic cavity demonstrating the left-sided chyle accumulation.

caemia and 6) immunosuppression [32-34]. Clinical suspicion of chylothorax exists when milky or white fluid is drained out of the thorax. This classical white appearance is also noted in pseudochylothorax [35]. Lymphangiography could be used to identify the spot of the chyle leakage or blockage $[35,36]$. Thoracentesis and laboratory analysis of the pleural fluid could lead to the diagnosis which is based on the presence of chylomicrons in the pleural fluid [33]. The presence of chylomicrons could be also speculated with the measurement of fluid cholesterol and triglyceride levels [12]. In recently published data near-infrared fluorescence imaging of thoracic duct and scintigraphy by orally administered 123 I BMIPP using SPECT/CT could reveal the chylous leakage [37].

Treatment of traumatic chylothorax is mainly conservative with chest drainage and total parenteral nutrition (TPN), followed by medium-chain triglyceride diet. This kind of treatment was supported by many authors with satisfactory results for their patients as chyle production reduced in a period of time of a few days to 3 - 4 weeks [11, 19, 21, 22, 24-26, 28-30, 38 ]. In some cases octreotide can be administrated with good results for the patients $[30,39,40]$. Surgical treatment should be followed only in the cases that chyle production is not reduced after the second to the third week of the conservative management. The goal of the operative treatment is the ligation of the thoracic duct as this was performed in a few cases in the literature [20,23].

\section{Conclusion}

Traumatic chylothorax after a thoracic spine fracture is a rare pathological entity and it could be present immediately after trauma or more than a month after injury as in our case. Diagnosis is simplified through laboratory exams of the milky excreted fluid. Treatment is conservative for the majority of the patients with total parenteral nutrition followed by mediumchain triglyceride diet.

\section{Conflicts of Interest}

The authors declare that they do not have any conflicts of interest.

\section{References}

1. McWilliams A, Gabbay E. Chylothorax occurring 23 years post-irradiation: literature review and management strategies. Respirology. 2000;5(3):301-303.

2. Doerr CH, Allen MS, Nichols FC, 3rd, Ryu JH. Etiology of chylothorax in 203 patients. Mayo Clin Proc. 2005;80(7):867-870.

3. Fogli L, Gorini P, Belcastro S. Conservative management of traumatic chylothorax: a case report. Intensive Care Med. 1993;19(3):176-177.

4. Maldonado F, Cartin-Ceba R, Hawkins FJ, Ryu JH. Medical and surgical management of chylothorax and associated outcomes. Am J Med Sci. 2010;339(4):314-318.

5. Sugimoto S, Tanaka M, Suzawa K, Nishikawa H, Toyooka S, Oto T, Ozaki T, et al. Pneumocephalus and chylothorax complicating vertebrectomy for lung cancer. Ann Thorac Surg. 2015;99(4):1425-1428.

6. Runge T, Borbely Y, Candinas D, Seiler C. Bilateral chylothorax following neck dissection: a case report. BMC Res Notes. 2014;7:311.

7. Bryant AS, Minnich DJ, Wei B, Cerfolio RJ. The incidence and management of postoperative chylothorax after pulmonary resection and thoracic mediastinal lymph node dissection. Ann Thorac Surg. 2014;98(1):232-235; discussion 235-237.

8. Borasino S, Diaz F, El Masri K, Dabal RJ, Alten JA. Central venous lines are a risk factor for chylothorax in infants after cardiac surgery. World J Pediatr Congenit Heart Surg. 2014;5(4):522-526.

9. Akpinar V, Duran FY, Duman E, Ozkalkanli MY, Duran O, Horsanali B. Bilateral chylhotorax after falling from height. Case Rep Surg. 2014;2014:618708.

10. Misthos P, Kanakis MA, Lioulias AG. Chylothorax complicating thoracic surgery: conservative or early surgical management? Updates Surg. 2012;64(1):5-11.

11. Pakula AM, Phillips W, Skinner RA. A case of a traumatic chyle leak following an acute thoracic spine injury: successful resolution with strict dietary manipulation. World J Emerg Surg. 2011;6:10.

12. de Beer HG, Mol MJ, Janssen JP. Chylothorax. Neth J Med. 2000;56(1):25-31.

13. Bolger C, Walsh TN, Tanner WA, Keeling P, Hennessy TP. Chylothorax after oesophagectomy. Br J Surg. 1991;78(5):587-588.

14. Orringer MB, Bluett M, Deeb GM. Aggressive treatment of chylothorax complicating transhiatal esophagectomy without thoracotomy. Surgery. 1988;104(4):720-726.

15. Snoeck JM, Vanderhoeft P, Verhest E, Heilporn A. [A rare cause of chylothorax: fracture luxation of the spine]. Acta Chir Belg. 1969;68(6):402-409.

16. Laaveg SJ, Sprague BL. Traumatic chylothorax, a compli- 
cation of fracture-dislocation of the spine. A case report. J Bone Joint Surg Am. 1978;60(5):708-709.

17. Wright PR, Gardner AM. Traumatic chylothorax; a case after dislocation of the thoracic spine. J Bone Joint Surg Br. 1952;34-B(1):64-67.

18. Leturgie C, Chamoun S, Ducable G, Watelet J, Testart J, Teniere P. [Traumatic chylothorax with dorsal spinal fracture. A case report (author's transl)]. J Chir (Paris). 1979;116(6-7):427-430.

19. Pai GP, Bhatti NA, Ellison RG, Rubin JW, Moore HV. Thoracic duct injury from blunt trauma. South Med J. 1984;77(5):667-668.

20. Di Natale I, Sartori C, Patelli G, Dal Pos R, Sorato R, Dal Pozzo A. [Traumatic chylothorax (apropos of a case following a closed vertebral-thoracic injury)]. Chir Ital. 1985;37(6):624-631.

21. Gartside R, Hebert JC. Chylothorax following fracture of the thoracolumbar spine. Injury. 1988;19(5):363-364.

22. Wei MY, Chow CS, Chen JB, Chen CL. Bilateral traumatic chylothorax: a complication of fracture-dislocation of the T-spine. Zhonghua Yi Xue Za Zhi (Taipei). 1993;52(3):194-197.

23. Allen SJ, Koch SM, Tonnesen AS, Bowman-Howard M, Khalil K. Tracheal compression caused by traumatic thoracic duct leak. Chest. 1994;106(1):296-297.

24. Bhat AL, Lowery GL. Chylous injury following anterior spinal surgery: case reports. Eur Spine J. 1997;6(4):270272.

25. Ikonomidis JS, Boulanger BR, Brenneman FD. Chylothorax after blunt chest trauma: a report of 2 cases. Can J Surg. 1997;40(2):135-138.

26. Lindhorst E, Miller HA, Taylor GA, Gotzen L. On the possible role of positive end-expiratory pressure ventilation in the treatment of chylothorax caused by blunt chest trauma. J Trauma. 1998;44(3):540-542.

27. Crnojevic LJ, Hodgetts TJ, Chambers D, Partridge RJ. Bilateral traumatic chylothorax: a complication of a fracture of the thoracic spine. Injury. 1997;28(9-10):681-682.

28. Montebugnoli M, Borghi B, Bugamelli B, Righi U, Boaron DM, Valbonesi M, Baroncini S. Salvage and reinfusion of chyle in closed chest injury. Int J Artif Organs.
1998;21(4):235-239.

29. Apostolakis E, Akinosoglou K, Koletsis E, Dougenis D. Traumatic chylothorax following blunt thoracic trauma: two conservatively treated cases. J Card Surg. 2009;24(2):220-222.

30. Sendama W, Shipley M. Traumatic chylothorax: A case report and review. Respir Med Case Rep. 2015;14:47-48.

31. Kamiyoshihara M, Ibe T, Kakegawa S, Sato K, Takise A, Takeyoshi I. Late-onset chylothorax after blunt chest trauma at an interval of 20 years: report of a case. Surg Today. 2008;38(1):56-58.

32. Servelle M, Nogues C, Soulie J, Andrieux JB, Terhedebrugge R. Spontaneous, post-operative and traumatic chylothorax. J Cardiovasc Surg (Torino). 1980;21(4):475-486.

33. Orange JS, Geha RS, Bonilla FA. Acute chylothorax in children: selective retention of memory T cells and natural killer cells. J Pediatr. 2003;143(2):243-249.

34. Dumont AE, Mayer DJ, Mulholland JH. The Suppression of Immunologic Activity by Diversion of Thoracic Duct Lymph. Ann Surg. 1964;160:373-383.

35. Ngan H, Fok M, Wong J. The role of lymphography in chylothorax following thoracic surgery. $\mathrm{Br} \mathrm{J}$ Radiol. 1988;61(731):1032-1036.

36. Ruan Z, Zhou Y, Wang S, Zhang J, Wang Y, Xu W. Clinical use of lymphangiography for intractable spontaneous chylothorax. Thorac Cardiovasc Surg. 2011;59(7):430435.

37. Takanami K, Ichikawa H, Takahashi S. Localization of lymphatic leakage site in chylothorax by thoracic duct scintigraphy by orally administered 123I BMIPP using SPECT/CT. Clin Nucl Med. 2012;37(4):403-405.

38. Bobbio P, Manfredi A, Salcuni PF. [Traumatic chylothorax. A further indication for total parenteral nutrition]. Minerva Chir. 1978;33(17):1115-1121.

39. Caverly L, Rausch CM, da Cruz E, Kaufman J. Octreotide treatment of chylothorax in pediatric patients following cardiothoracic surgery. Congenit Heart Dis. 2010;5(6):573-578.

40. Sharkey AJ, Rao JN. The successful use of octreotide in the treatment of traumatic chylothorax. Tex Heart Inst J. 2012;39(3):428-430. 